\title{
Erratum to: Glutamate is the chemotaxis-inducing factor in placental extracts
}

\author{
Rahul Gupta $\cdot$ Dhrubajyoti Chattopadhyay
}

Published online: 21 April 2010

(C) Springer-Verlag 2010

Erratum to: Amino Acids (2009) 37:359-366

DOI 10.1007/s00726-008-0162-2

Unfortunately the article "Glutamate is the chemotaxisinducing factor in placental extracts" by R. Gupta and D. Chattopadhyay, has been cited twice in the same issue (on pp 271-277, doi:10.1007/s00726-008-0143-5; and on pp 359-366, doi:10.1007/s00726-008-0162-2). Both the articles have exactly the same content.

For citation, please use article doi:10.1007/s00726-0080143-5.

The online versions of the original articles can be found under doi:10.1007/s00726-008-0162-2 and doi:10.1007/s00726-008-0143-5.

R. Gupta $\cdot$ D. Chattopadhyay $(\bowtie)$

Dr. B. C. Guha Centre for Genetic Engineering and Biotechnology, Department of Biochemistry,

University of Calcutta, 35 B. C. Road, Kolkata 700 019,

West Bengal, India

e-mail: d_jc@sify.com

R. Gupta

Albert David Limited, 5/11, D. Gupta Lane,

Kolkata 700 050, India 